\title{
Chapter 12 \\ Dual Agency, Commission Levels, and the Effect on Sale Price in Residential Real Estate Market: A Questionnaire Survey on Real Estate Brokers in Japan
}

\author{
Keiichi Shirakawa and Toshiyuki Okoshi
}

\begin{abstract}
In residential real estate market, agents have an incentive to steer their clients to their own listings or buyers rather than offering the best value transaction, which is derived from allowing dual agency and information asymmetry among buyers, sellers, and agents. We estimated the commission levels and sale prices of real estate brokers through a questionnaire survey and found that seven out of ten brokers are closing dual-agency deals and lowering sale prices. We could not find any effects of the number of employees, location of office, and major types of contract on dual agency.
\end{abstract}

Keywords Real estate brokerage $\cdot$ Dual agency $\cdot$ Information asymmetry $\cdot$ Agency problem

\subsection{Background and Purpose}

\subsubsection{The Kakoikomi Problem}

How to increase the share of existing homes in Japan's housing market has been a major issue. According to the Housing and Land Survey of the Statistics Bureau, Ministry of Internal Affairs and Communications, the share of existing homes has accounted for $10-20 \%$ in the housing market for almost the past 20 years.

\footnotetext{
K. Shirakawa $(\bowtie)$

Land Institute of Japan, Tokyo, Japan

e-mail: shirakawa@tochi.or.jp

T. Okoshi

Land Institute of Japan, Tokyo, Japan

Reitaku University, Chiba, Japan

e-mail: tokoshi@reitaku-u.ac.jp 
It has been pointed out that one of the obstacles for stimulating existing home market is Kakoikomi. Kakoikomi is the act whereby a seller's agent hides the existence of other potential buyers (clients of competing agents) from the seller by telling a lie, for example, "I am already in negotiations with an another buyer," in order to close a dual-agency deal and earn commissions from both buyer and seller in one transaction. ${ }^{1}$ Dual agency is broker's representation of both the seller and the buyer in the same transaction. Since the broker does not inform the client (seller or buyer) that he or she is acting as a dual agent in such cases, information asymmetry arises between the broker and the client in relation to the broker's behavior, resulting in a possibility that the transaction may prove disadvantageous for the client. In many states in the US, the broker is legally obliged to inform clients that he or she represents both clients when acting as a dual agent. ${ }^{2}$ (Although there is no distinction between the agency agreement and the mediating agreement in Japan's real estate transactions, dual agency and dual mediation are not necessarily the same unless the transaction has come into effect. However, the two are indistinguishable for cases where transactions have already concluded, then we call both "dual agency.")

According to Jutaku-Shimpo, Inc., the average commission level of the 10 major residential real estate brokerage companies in 2015 was $4.02 \%$, which exceeded the upper limit for a single-agency transaction of $3 \%+60,000$ yen. If all transactions were under a single agency, the average commission level per transaction should be $3 \%+60,000$ yen at most. ${ }^{3}$

\subsubsection{Information Asymmetry in Existing Home Market}

The problems caused by information asymmetry in existing home market can be classified into two categories: problems of hidden information and problems of

\footnotetext{
${ }^{1}$ The Real Estate Brokerage Act imposes a duty on the broker to register related data with the Real Estate Information Network System (REINS) when the exclusive mediation agreement is concluded and prohibits the broker from intentionally concealing information from the other party of the contract or monopolizing it.

${ }^{2}$ In the US, as a result of state's own legislation, there are (1) several states that, while permitting various types of dual agency, oblige the broker to disclose to both the seller and the buyer that he or she is a dual agent (e.g., New York), (2) a small number of states permit designated dual agency, i.e., they prohibit dual agency by the same person, but permit the dual agency within the same branch or the same firm (e.g., Colorado, Maryland), and (3) other states that, instead of prohibiting dual agency, permit transaction brokerage that does not legally represent either the seller or the buyer (e.g., Florida) (Kadiyali et al. 2014). The effectiveness of the obligation by the state laws is secured through the possibility of nullification or suspension of real estate agents' or brokers' licenses that are prescribed through such state laws (Olazabal 2003, pp. 70-71).

${ }^{3}$ The upper limit for the mediation fee prescribed in accordance with the Real Estate Brokerage Act is $5 \%$ for transaction amounts under 2 million yen, $4 \%$ for transaction amounts under 4 million yen, and $3 \%$ for transaction amounts of 4 million yen or more (all excluding tax); when an additional amount below 4 million yen is aggregated, it results in $3 \%+60,000$ yen.
} 
hidden action. The former are the problems between the seller and the buyer, whereas the latter are the problems between the seller/buyer and the broker.

\section{The Problems of Hidden Information}

In a real estate property transaction, the seller has much more information about the property than the buyer. The seller knows much more on the condition of the property that is not evident on the surface as well as the transaction history, which the seller obtained when he or she purchased the property in the past. By contrast, the buyer faces the risk of purchasing poor-quality property, which reduces the level of willingness to pay for the property. Consequently, even if the seller invests in an old property, such investment is not appropriately evaluated by the market, resulting in adverse selection and the transactions of only poor-quality properties, causing the market to be full of lemons. ${ }^{4}$ Thus, the quality of existing homes supplied to the market declines, and existing home market becomes inactive.

In the real estate market, where there tends to occur adverse selection with hidden information, rather than conducting direct transactions between the seller and the buyer, it is effective to engage full-time real estate brokers with experience and knowledge about similar real estate transactions as intermediaries, provided that the problems of the hidden action referred to later can be ignored. Buyers can get the property information and past transaction history through brokers, enabling them to better negotiate with the seller. The existence of brokers contributes to prevent the market from becoming full of lemons by avoiding adverse selection.

\section{The Problems of Hidden Action}

The problem of adverse selection with hidden information occurs regardless of the intent of the seller or the seller's broker. By contrast, the problem of moral hazard emerges when brokers act to conceal potential seller or buyer to their client and is intentionally instigated by brokers.

The broker can act as a dual agent and control the transaction to be made between the specific buyer and seller, both of whom are represented by the broker, by not giving the buyer enough information, such as the types of properties being sold and the types of sellers in the market, and by not informing the seller of the price at which buyers will purchase property in the market. This is referred to as Kakoikomi. This type of behavior cannot be avoided as long as the seller and buyer are unable to monitor it. If the broker succeeds in closing a dual-agency deal, the broker can obtain a fee of up to $3 \%+60,000$ yen from the seller as well as from the buyer for one transaction; consequently, brokers have an incentive to pursue a dual-agency deal.

\footnotetext{
${ }^{4}$ Yamazaki (1997), Takahashi (2009), and Nakagawa (2014) identify similar problems in the real estate market.
} 
The mitigation of information asymmetry between the seller and the buyer by promoting real estate transactions through mediation has merits for both parties. In particular, in a dual-agency deal, as noted by Kadiyali et al. (2014), the broker knows such as the preferences of both sides which can accelerate and improve the efficiency of negotiations during the transaction ${ }^{5}$. However, Kakoikomi occurs if dual agency is permitted and the broker is able to intentionally hide potential sellers and buyers. The merits of the mediation transaction over the direct transaction are eventually offset by such demerits.

\section{The Impact of Dual Agency on Sale Price}

If there were a legal requirement for the broker to disclose when acting as a dual agent, as there is in the US, the seller as well as the buyer would be able to confirm if the transaction proposed by the broker is disadvantageous compared to proposals by other brokers. And if so, the buyer or seller could decline the mediation. ${ }^{6}$ In addition, for the broker, too, there is an incentive to conduct fair mediation transactions that are not disadvantageous to either sellers or buyers. Therefore, any difference in the sale price is unlikely, regardless of whether the broker closes a dual-agency deal or not. However, this requires following conditions: (1) the broker shall take a stance that is not biased toward either the seller or buyer and (2) there shall be no difference in the negotiation power between the selling and buying brokers. Kadiyali et al. (2014) argue that whether dual agency affects sale price to be higher or lower depends on which side (i.e., the seller side or the buyer side) is taken by the broker, so its impact is not necessarily definitive. If taking the seller side, the sale price will be higher and the commission received increases proportionally, whereas if the buyer side is taken, the sale price will be lower in the sense that the broker fails to mediate the transaction with the most desirable customer for the broker. Nevertheless, having said this, if the broker fails to lead the transaction to his or her own customer, the impact on the sale price will be zero.

Whether brokerage companies closing dual-agency deals are successfully raising the sale price to increase their mediation fee income and what types of companies

\footnotetext{
${ }^{5}$ Kadiyali et al. (2014) observe the merits of dual agency as being (1) information and transaction efficiency as well as (2) an expansion of the property transaction mediated by brokers. Conversely, the demerits are cited as being (1) incentive to induce the seller to make a transaction with a buyer as one's own client at a lower transaction price than the maximum amount that the (potential) buyers are willing to pay, (2) the selective provision of information to clients, and (3) the pressure on both the seller and the buyer. All these demerits can be a cause for Kakoikomi.

${ }^{6}$ Regardless of whether there is an obligation for prior notification when closing a dual-agency deal, if a status monitoring that enables the seller to browse REINS and confirm the buy inquiries for his or her own property is available, the seller's broker is unable to behave in a manner that is disadvantageous for his or her client, such as causing a transaction to be concluded at a price that is below the market price.
} 
successfully increase the probability of concluding dual-agency transactions (hereinafter referred to as matching probability) should be clarified by empirical survey.

\subsubsection{Research Purpose}

Based on the above discussion, the existence of two conditions, that (1) dual agency is permitted and (2) the client (seller, buyer) is unable to monitor the broker, is considered to increase the matching probability through dual agency and as a result, generate high fee income as well as impact the sale price.

However, there is an insufficient amount of quantitative research regarding the behavior of transaction participants in Japan's real estate market, and there is still no clear information on the current status of dual agency in existing home market.

Thus, this research first quantitatively clarifies the state of mediated transactions in Japan and then considers (1) the attributes of the company who closes a dualagency deal and (2) how dual agency affects sale price.

In Sect. 12.2, we clarify how transactions are mediated where dual agency has been disclosed based on existing studies of dual agency in the US. In Sect. 12.3, we estimate the frequency of dual-agency deals in Japan by taking the mediation commission level as a proxy variable, based on a questionnaire survey on brokers. In Sect. 12.4, we analyze the impact on the commission level by the attributes of the company, and in Sect. 12.5, we examine the impact of dual agency on the average contract amount.

\subsection{The Impact of Dual Agency in the US}

Gardiner et al. (2007) compared 1,989 transaction data from 1977 to 1980 with 1,858 transaction data from 1987 to 1989 around the time that state law was enacted in 1984 requiring real estate agents engaged in dual-agency relationships to disclose this fact to both the seller and the buyer in Honolulu, Hawaii. They indicated that dual agency had the effect of reducing the sale price, and that such effect significantly reduced (from around $8.0 \%$ to $1.4 \%$ ) following the enactment of the state law. This research can also be taken to suggest an expected effect of mandatory disclosure of dual agency in Japan.

Evans and Kolbe (2005) reported that, based on a sample of 4154 houses, each of which was sold more than once between 1997 and 2003 in Memphis, Tennessee, the impact of dual agency on the sale price had no statistical significance for the first transaction, whereas there was a small yet significant impact for the second transaction.

Kadiyali et al. (2014) clarified that dual agency had no impact on the sale price based on a regression analysis that took the sale price as the dependent variable with 10,888 transaction data from 2004 to 2007 in Long Island, New York (Table 12.1). 
Table 12.1 Comparison of the state of dual-agency and single-agency transactions in Long Island, New York

\begin{tabular}{l|l|l}
\hline & Dual agency & Single agency \\
\hline Mean of sales price (\$) & 570,957 & 566,841 \\
\hline Mean of list price (\$) & 603,003 & 591,381 \\
\hline Mean of time-to-sale (days) & 82.0 & 84.2 \\
\hline Number of samples & 5247 & 5641 \\
\hline
\end{tabular}

Source: Kadiyali et al. (2014), p. 178

Note: About half $(48 \%)$ of all transactions occurred via dual agency; dual-agent deals (26\%), within-branch deals (19\%), and within-agency deals $(3 \%)$

However, conducting additional analysis by adding the list price as a variable, they note that dual agency has no net effect on the sale price due to the combination of the following two effects: (1) the broker who concludes a dual-agency transaction obtains a higher sale price by exploiting information on buyer clients' preference, and (2) the dual agent favors the buyer over the seller through the negotiation process, by leaning on the seller to accept the buyer's offer or by disclosing confidential information only to the buyer, etc.

As noted above, according to previous research that examined the impact of dual agency in the US, it is clear that no difference exists between the sale prices of dual and single agencies. In this regard, although there has been no past research concerning the degree of impact on the sale price, adequate information disclosure can be considered one of the main factors in reducing the sale price differential.

\subsection{The State of Mediation Fee Setting in Japan}

\subsubsection{Questionnaire Design}

In Japan, there is no comprehensive property information data base such as the Multiple Listing Service in the US. Therefore, it is extremely difficult to directly clarify the mediation commission levels set by each company for each transaction.

Consequently, this questionnaire survey is conducted on a broker-by-broker basis, with the normal level of mediation fee per property for each company calculated by dividing the total amount of mediation fee by the total contract amount of brokerage in 2014. In this study, the commission level is taken to be a proxy variable for whether a dual-agency deal is closed or not. In particular, if the commission level is higher than the upper limit that can be generated for a single agency of $3 \%+60,000$ yen for a company, it is likely that said the company has been a dual agent. ${ }^{7}$

\footnotetext{
${ }^{7}$ Since laws and ordinances prescribe only the upper limit for commission level and lower commission levels are possible in actual transactions, dual agency cannot be determined only from the value of the commission level, and we can only indicate the possibility of dual agency. For example, even if the commission level were below 3\%, it may mean that the broker is receiving
} 
At the time the target list of brokers is to be created, there is no public list that covered the brokers nationwide. Therefore, we obtained a list of brokers to the extent that their cooperation was forthcoming and created a target list of companies. First, we obtained a list of survey targets in the Real Estate Industry Diffusion Survey conducted by the Land Institute of Japan and identified 73 companies (large enterprises and SMEs) engaged in real estate business in three major cities (Tokyo, Osaka, and Nagoya) and major cities in other areas. Second, 326 companies participating LIXIL ERA network and Renewal Brokerage Agency Inc. were obtained. Third, 101 companies participating Association of Real Estate Agents of Japan (Fudosan Ryutsu Keiei Kyokai or FRK) were obtained from the website, HomeNavi. ${ }^{8}$ Fourth, 527 companies were obtained from the Executive Officers Register (FY2012 and FY2013) of the Prefectural Real Estate Associations (Todofuken Takuchi Tatemono Torihikigyo Kyokai), which is published on the Internet. ${ }^{9}$ Adjustments for duplication were made for these companies, resulting in a final target list of 1000 companies.

We sent a questionnaire by post during the period from January 13 to February 10,2015 . The number of valid responses was 247 companies (a response rate of $24.7 \%)$.

Most of responded companies were small brokers; of these companies, approximately $70 \%$ had been in operation for 25 years or more, around $60 \%$ had five employees or fewer, and more than $80 \%$ had only one office (Table 12.2). ${ }^{10}$

\footnotetext{
an individual fee of $1.5 \%$ from the seller as well as from the buyer. In addition, for properties with low sale price, the fixed portion of the fee $(60,000$ yen) has a large impact on the commission level (e.g., in the case of a 6-million-yen property, 60,000 yen $=1 \%$ ).

${ }^{8}$ http: //www.homenavi.or.jp/corp

${ }^{9}$ The extracted numbers are Hokkaido, 20; Iwate, 10; Miyagi, 20; Fukushima, 10; Ibaragi, 20; Saitama, 35; Chiba, 35; Tokyo, 62; Kanagawa, 35; Niigata, 15; Ishikawa, 15; Aichi, 50; Kyoto, 30; Osaka, 60; Hyogo, 30; Hiroshima, 30; Tokushima, 20; and Fukuoka, 30.The addresses of businesses located in Miyagi, Saitama, Chiba, Tokyo, Aichi, Kyoto, Osaka, Hyogo, Hiroshima, and Fukuoka are from a web search based on the name mentioned in the Executive Officers Register or their trade names (company names).

${ }^{10} \mathrm{We}$ compared the number of employees and the number of years of operation in our data with the data of registered real estate brokers at the end of FY2015 published by the Real Estate Transaction Improvement Organization. As a result of the test of independence, our data contains significantly less sole proprietors and more brokers with long years of operation. Note that there was no significant location bias of companies. In the above analysis, the small number of sole proprietors and the large number of brokers with long years of operation make it necessary to consider the possibility that these boosted the overall matching probability of dual agency.
} 
Table 12.2 Breakdown of responding companies

\begin{tabular}{l|c|c|l|l|l|l|r|r}
\hline \multicolumn{2}{l}{ Number of years of operation } & \multicolumn{3}{l|}{ Number of employees } & \multicolumn{3}{l}{ Number of offices } \\
\hline & $\#$ & $\%$ & & $\#$ & $\%$ & & $\#$ & $\%$ \\
\hline 1 & 3 & 1.2 & 1 & 17 & 6.9 & 1 & 208 & 84.2 \\
\hline $1-4$ & 9 & 3.6 & $2-5$ & 126 & 51.0 & $2-5$ & 29 & 11.7 \\
\hline $5-9$ & 13 & 5.3 & $6-10$ & 49 & 19.8 & $6-10$ & 3 & 1.2 \\
\hline $10-24$ & 52 & 21.1 & $11-50$ & 40 & 16.2 & $11-50$ & 4 & 1.6 \\
\hline $25-$ & 170 & 68.8 & $51-100$ & 6 & 2.4 & $51-$ & 3 & 1.2 \\
\hline Total & 247 & 100.0 & $101-1000$ & 6 & 2.4 & Total & 247 & 100.0 \\
\hline & & & $1001-$ & 3 & 1.2 & & & \\
\hline & & & Total & 247 & 100.0 & & & \\
\hline
\end{tabular}

Note: Business offices of Article 8 (2) (v) of the Real Estate Brokerage Act

Table 12.3 Basic statistics

\begin{tabular}{l|l|r|r}
\hline & Mean & S.E. & Median \\
\hline Number of contracts & 407.28 & 3331.3 & 10 \\
\hline Total contract amount (billion yen) & 19.895 & 137.5 & 0.3 \\
\hline Average contract amount (million yen/transaction) & 33.098 & 46.248 & 21.117 \\
\hline Commission level (\%) & 4.1367 & 1.6013 & 3.85 \\
\hline
\end{tabular}

\subsubsection{Relationship Between Dual Agency in the Commission Level and Contract Amount}

The total amount of mediation fee and the contract amount were obtained from 155 companies out of the 247 companies. The mean of average contract amount calculated by each company by dividing the total contract amount by the number of contracts (calculating the dual-agency transaction as one transaction) was 33.1 million yen/transaction, with a commission level of $4.1 \%$ (Table 12.3). As illustrated in Fig. 12.1, $70 \%$ of companies are taking a fee on average of more than $3 \%$ per transactions for mediation. ${ }^{11}$

Figure 12.2 illustrates the relationship between the calculated mediation commission level and the average contract amount calculated by dividing the total contract amount by the number of contracts. The correlation coefficient is -0.238 ; the result of a test of no correlation had $t$-value $=-3.03$ and $P$-value $=0.00284$. There was a weak correlation in that companies with high mediation commission levels tended to have low average contract amounts.

\footnotetext{
${ }^{11}$ Twenty-one companies had mediation commission levels in excess of $6 \%$, and the highest value was $10 \%$. The maximum fee that can be obtained from dual agency is $6 \%+120,000$ yen; for example, assuming a transaction of a 4-million-yen property with dual agency, the fee would be a maximum of $240,000(6 \%$ of 4 million yen) $+120,000=360,000$ yen or as high as $9 \%$ of the sale price. Given the impact of the fixed amount of 120,000 yen, a commission level in excess of $6 \%$ cannot necessarily be considered as an unusual value.
} 
Fig. 12.1 Histogram of mediation commission levels

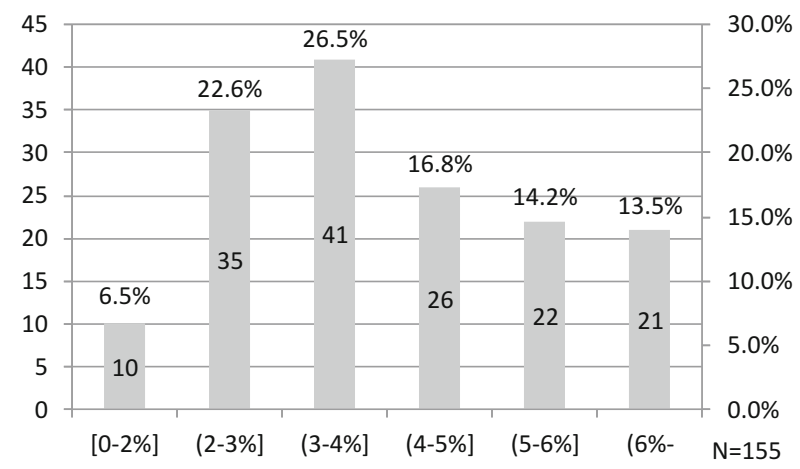

Fig. 12.2 Mediation commission level and average contract amount

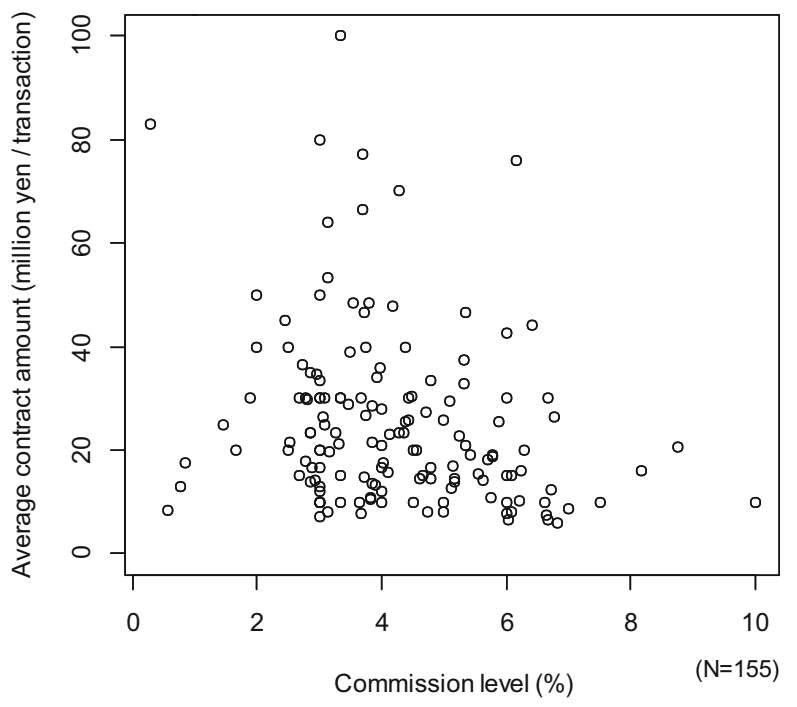

Companies with commission levels below 3\% are not only companies that handle high value properties with large average contract amounts but also include companies handling small value properties with small average contract amounts. In the case of companies handling small value properties, it is thought that they would be unable to secure profits unless they set mediation commission levels at the upper limit. However, it became evident that there are companies actually that keep commission levels below the upper limit even among companies handling small value properties. 
Table 12.4 Response concerning the basis for setting the mediation commission level

\begin{tabular}{l|r|r|l}
\hline Criteria for commission level & \multicolumn{1}{|l|}{$\begin{array}{l}\text { Average } \\
\text { commission level }\end{array}$} \\
\hline Set at the upper limit on the law & 138 & 89.0 & 4.2215 \\
\hline Apply the company's own standard & 3 & 1.9 & 3.2717 \\
\hline $\begin{array}{l}\text { Although there is a standard, the actual amount is reduced } \\
\text { according to the situation }\end{array}$ & 9 & 5.8 & 3.4012 \\
\hline No answer & 5 & 3.2 & 3.64 \\
\hline Total & 155 & 100.0 & \\
\hline
\end{tabular}

\subsubsection{Proportion of Companies Setting the Commission Level at the Upper Limit}

When brokers close dual-agency deals, they do not necessarily set their fees at the upper limit. Therefore, even if the commission level calculated from the final contract amount and fee income is $3 \%$, it is possible that the broker charges the seller and the buyer separately, for example, a fee of $1.5 \%$ each. Consequently, estimating the mediation commission level from the above method alone cannot provide the exact level of brokers' fee for specific transactions.

We asked directly the companies that responded to the question concerning the mediation commission level whether they charged the upper limit of the fee. Over $80 \%$ of those companies said that they set the commission level at the upper limit on the law (Table 12.4). In addition, upon calculating the average commission level for each respective item, all exceeded 3\% and the ANOVA result showed no significant difference in the average commission levels among the groups $(F$-value $=1.585, P$ value $=0.208$ ). Without being able to increase the commission level, it is necessary for brokers to close a dual-agency deal to obtain a higher fee from a single transaction. Many brokers are constantly taking the fee at the upper limit, which suggests that there is a strong incentive for most brokers to pursue dual-agency deals.

\subsection{Impact of Company Attributes on the Mediation Commission Level}

\subsubsection{Impact from the Scale of the Company and Market}

To conclude a dual-agency transaction requires an increase in the matching probability by either the broker having adequate numbers of sellers and buyers on its customer list or there being adequate numbers of sellers and buyers in the market. ${ }^{12}$

\footnotetext{
${ }^{12}$ If the market is large, there will be an increase in the matching probability not only for dual agency but also for single agency.
} 
Table 12.5 Regression analysis taking the commission level as the dependent variable

\begin{tabular}{l|l|l|l|l}
\hline \multirow{2}{*}{} & \multicolumn{3}{l}{ (A) all companies $(N=155)$} & (B) set at the upper limit $(N=138)$ \\
\cline { 2 - 5 } & Coef. & S.E. & Coef. & S.E. \\
\hline Intercept & 0.042380 & $0.002032 * * *$ & 0.042488 & $0.002105^{* * *}$ \\
\hline Dummy of \# of employees & (baseline) & - & (baseline) & - \\
\hline $1-5$ & -0.002767 & 0.002729 & -0.002562 & 0.002871 \\
\hline $6-10$ & -0.010400 & $0.005467 *$ & -0.009257 & 0.005843 \\
\hline $11-$ & 0.001360 & 0.002635 & 0.002801 & 0.002843 \\
\hline Dummy of location & (baseline) & - & (baseline) & - \\
\hline Major city area & 0.02596 & & 0.02297 & \\
\hline Other area & 0.006603 & & 0.001093 & \\
\hline$R^{2}$ & Adjusted $R^{2}$ & $*$ &
\end{tabular}

Thus, we conducted a regression analysis with the mediation commission level which we used as an indicator of dual agency as dependent variable, and the number of customers covered by each broker and the size of the market as independent variables. $^{13}$

Since the number of customers covered by each broker is not known from this survey, the number of employees is used as a proxy variable to indicate the scale of a company's sales. The dummy variables that group the number of employees into 1 to 5,6 to 10, and 11 or more are taken to be independent variables. In addition, as a proxy variable to indicate the scale of the market for the location of brokers, companies that provided their addresses in the questionnaire (200 out of $247 \mathrm{com}-$ panies) were assigned dummy variables that grouped the locations as either being inside or outside the prefectures (Tokyo, Kanagawa, Chiba, Saitama, Aichi, Osaka, Kyoto, and Hyogo) located in or near the three major cities (Tokyo, Osaka, and Nagoya).

The results are presented in Table 12.5 (A). The dummy for 11 or more employees has statistical significance at $10 \%$ and is recognized as pushing down the commission level by around $1 \%$.

As discussed in Sect. 12.3.3, there are cases of dual-agency transactions being closed with reduced commission level. Therefore, when using commission level as a proxy variable for dual agency, a certain degree of measurement error is generated. We checked the robustness by conducting another analysis limiting the sample to the companies that responded that they set the commission level at the upper limit. The result is presented in Table 12.5 (B). We couldn't find any significance for both the dummy of employees and the dummy of location. The significance of the dummy for 11 or more employees disappeared because the effect of boosting the commission level from dual agency was not as large as the downward impact on commission

\footnotetext{
${ }^{13}$ We used R3.3.2 for estimation. The listwise deletion was used for the missing value. Hereinafter, the same shall apply.
} 
level from both dual and single agency for large companies. Unlike we supposed above, the significance of the dummy for 11 or more employees disappeared.

\subsubsection{Impact Due to Differences in the Main Types of Mediation Agreements}

There are three types of contracts for mediation agreements exchanged when requesting a real estate broker to mediate: non-exclusive mediation agreement, exclusive mediation agreement, and privileged and exclusive mediation agreement. A non-exclusive mediation agreement enables the seller to request another real estate company to act as an intermediary, whereas an exclusive mediation agreement does not allow such a request. In addition, although the seller can make a transaction with a counterparty that he or she finds on their own under an exclusive mediation agreement, this is not allowed under a privileged and exclusive mediation agreement.

In the case of a non-exclusive agreement, brokers compete with rival companies for concluding the contract, so a fee is not necessarily received. Brokers tend to benefit by making a dual-agency deal with their client rather than urging to find buyers who are able to contract at higher prices. However, in the case of an exclusive mediation agreement, where a fee will definitely be received from the seller's side, the broker have an incentive to generate a dual-agency deal by urging to sell to his or her client in less-than-one-week period prior to REINS registration. Moreover, in the case of an exclusive mediation agreement, there is a stronger binding force on broker's behavior such as the broker is the only company who can post advertisements of its real estate. Based on such a relationship, we have made two hypotheses: (1) companies with non-exclusive agreements find it easy to make a dual-agency deal and (2) companies with exclusive agreements find it easy to make a dualagency deal.

We conducted a regression analysis with the commission level as the dependent variable and a dummy variable divided by the proportion of number of contracts in mediation into two groups of at least $75 \%$ or fewer than $75 \%$ for each of non-exclusive mediation agreement, exclusive mediation agreement, or privileged and exclusive mediation agreement as independent variables. The results are presented in Table 12.6. No significant relationship was evident for commission levels with any of non-exclusive mediation agreement, exclusive mediation agreement, or privileged and exclusive mediation agreement. 
Table 12.6 Regression analysis from the dummy of $75 \%$ or more for each type of mediation agreement

\begin{tabular}{l|r|l}
\hline & \multicolumn{1}{|l|}{ Coef. } & \multicolumn{1}{l}{ S.E. } \\
\hline Intercept & 0.045358 & $0.002399 * * *$ \\
\hline Dummy of non-exclusive mediation $(\geq 75 \%=1,<75 \%=0)$ & -0.005651 & 0.004095 \\
\hline Dummy of exclusive mediation $(\geq 75 \%=1,<75 \%=0)$ & -0.004940 & 0.003159 \\
\hline $\begin{array}{l}\text { Dummy of privileged and exclusive mediation }(\geq 75 \%=1, \\
<75 \%=0)\end{array}$ & -0.005439 & 0.004073 \\
\hline$R^{2}$ & 0.03282 & \\
\hline Adjusted $R^{2}$ & 0.009035 & \\
\hline & & $N=126$ \\
\hline
\end{tabular}

$* * *: p<0.01, * *: p<0.05, *: p<0.1$

Table 12.7 Descriptive statistics for each variable by mediation commission level group

\begin{tabular}{l|l|l|l}
\hline & $\begin{array}{l}\text { Single } \\
\text { agency }\end{array}$ & $\begin{array}{l}\text { Partial dual } \\
\text { agency }\end{array}$ & $\begin{array}{l}\text { All dual } \\
\text { agency }\end{array}$ \\
\hline$N$ & 22 & 92 & 24 \\
\hline Mean of \# of contracts & 121.82 & 828.04 & 20.542 \\
\hline Mean of total contract amount (billion yen) & 4.8323 & 33.597 & 0.33104 \\
\hline $\begin{array}{l}\text { Mean of average contract amount (million } \\
\text { yen/transaction) }\end{array}$ & 31.877 & 29.944 & 19.054 \\
\hline Mean of commission level (\%) & 2.2192 & 4.0434 & 6.7393 \\
\hline
\end{tabular}

\subsection{Impact of Dual Agency on the Sale Price}

To examine the impact of dual agency on the sale price, we conducted a regression analysis by separating respondents into a single-agency group with less than $3 \%$ trade mediation commission level, a partial dual-agency group with 3-6\% commission level, and an all dual-agency group with $6 \%$ or more commission level, taking the dependent variable to be the average contract amount per transaction and independent variables being these group dummies (Table 12.7).

The results are presented in Table 8 (A). The partial dual-agency group dummy and the all dual-agency group dummy had negative significant effect. This corresponds to the weak negative correlation between the commission level and contract amount seen in Sect. 12.3.2. In addition, contract amount was significantly higher in major city areas. As with Sect. 12.4.1, a certain measurement error is included when using commission level as a proxy variable for dual agency, so we modified the model 2 in Table 12.8 (A), limiting to companies that set the fee at the upper limit. The results are presented in Table 12.8 (B). Although the significance of the dummy of location vanished and the dummy of 11 or more employees turned significant, the dummy for the partial dual-agency group and the dummy for the all dual-agency group remained the same. 


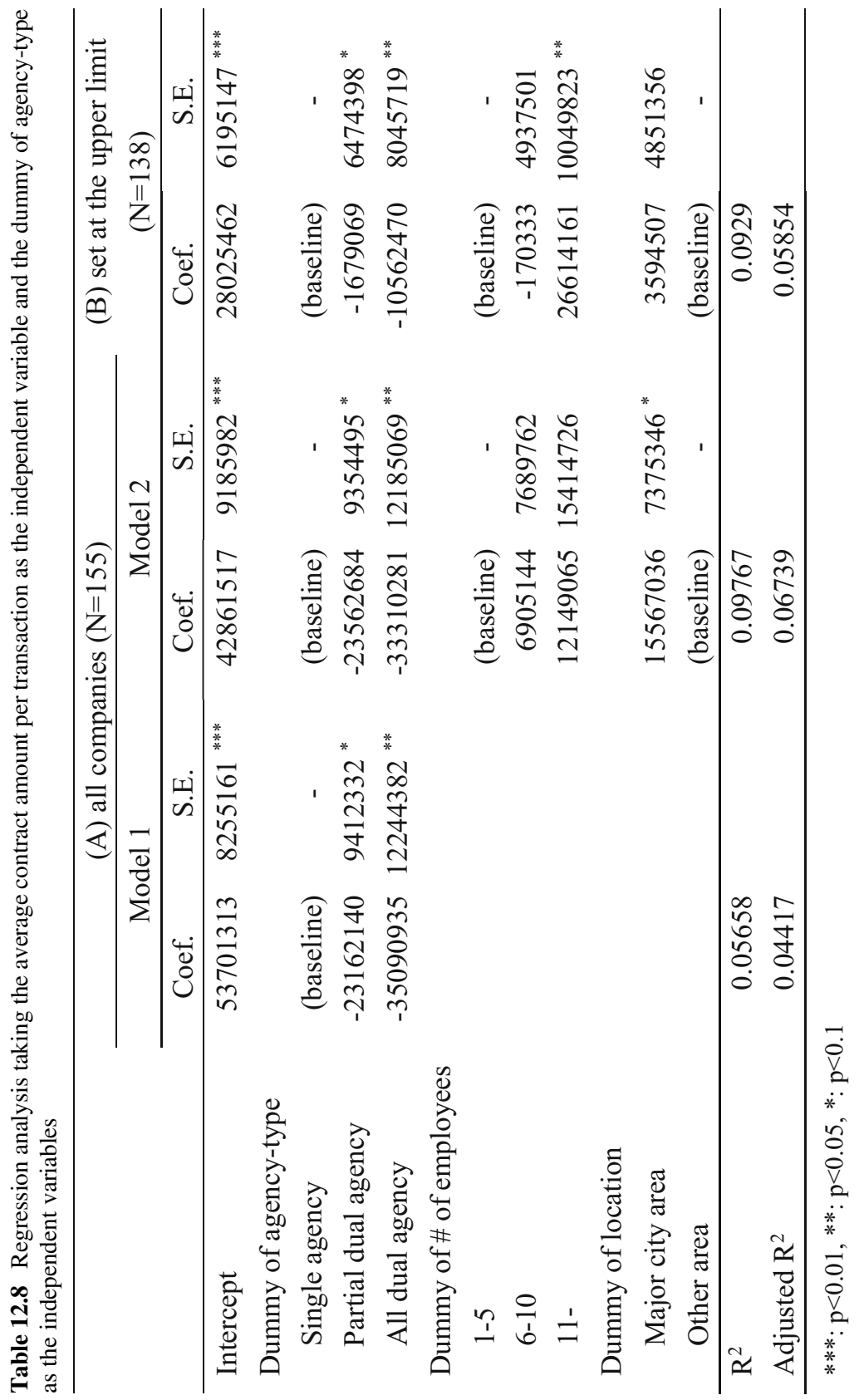




\subsection{Conclusion and Future Issues}

In the US, where disclosure concerning dual agency is obliged, there is no price difference evident between dual and single agency. However, in Japan, where Kakoikomi with dual agency is easier owing to more incomplete information, we show that $70 \%$ of companies are closing dual-agency deals, resulting in a lower sale price. In addition, the size of companies, the scale of the market, and the differences in the main types of mediation agreement are not necessarily the causes for increasing the matching probability of dual agency. The reduction of the sale price in dual agency suggests that brokers raise moral hazard in relation to sellers. To improve disadvantageous circumstances to sellers, initiatives are required such as a system for status monitoring where sellers can confirm the state or property transactions, that REINS has started.

Nevertheless, the dual-agency group dummy is merely an indirect indictor of dual agency, and one should be wary of accepting this conclusion at face value.

Further, there is an endogeneity problem in that the quality of property, which is not an observable variable, may possibly have an impact not only on sale price but also the choice of dual or single agency. The change in the significance of the dummy of employees and the dummy of location could also be attributed to the influence of the quality of property. However, variables that are independent of the quality of properties handled by such companies were not included in this survey; consequently, endogeneity cannot be verified. Nonetheless, at the very least, there is no denying the possible existence of endogeneity.

There are three points that could not be examined in our study. First is the ratio of buyer and seller mediation by each broker. Even if there are large numbers of customers, when there is a bias toward sellers or buyers, the matching probability of dual agency is considered not to increase. In addition, brokers that only handle buyers as customers are unable to propose a dual-agency deal in the first place. Second is the impact by dual agency on the number of days required for contract closing. Third, as our target list of questionnaire was not on the units of transactions but on the units of companies, we could not directly examine the impact of the different types of mediation agreement on mediation transactions, and it was also impossible to examine the impact of the attributes of the property such as size and facilities. These are all remained for future research.

Acknowledgments We would like to extend our appreciation to businesses that responded to the questionnaire survey and to all the participations of the conference and anonymous referees who provided very constructive comments when working on this research.

\section{References}

Evans R, Kolbe P (2005) Homeowners' repeat-sale gains, dual agency and repeated use of the same agent. J Real Estate Res 27(3):267-292 
Gardiner J, Heisler J, Kallberg JG, Liu CH (2007) The impact of dual agency. J Real Estate Financ Econ 35(1):39-55

Kadiyali V, Prince J, Simon DH (2014) Is dual agency in real estate a cause for concern? J Real Estate Financ Econ 48:164-195

Nakagawa M (2014) Revitalizing existing house market and the visions for the market in the future. Housing Financ Mag 30:26-33. (in Japanese)

Olazabal A (2003) Redefining realtor relationships and responsibilities: the failure of state regulatory responses. Harv J Legis 40:65-132

Takahashi T (2009) Inefficiency of distribution from incomplete real estate information: an economist's view. Urban Housing Sci 66:18-22. (in Japanese)

Yamazaki F (1997) The function of existing house market and cost of construction. Quart J Housing Land Econ 26:10-19. (in Japanese)

Open Access This chapter is licensed under the terms of the Creative Commons Attribution 4.0 International License (http://creativecommons.org/licenses/by/4.0/), which permits use, sharing, adaptation, distribution and reproduction in any medium or format, as long as you give appropriate credit to the original author(s) and the source, provide a link to the Creative Commons licence and indicate if changes were made.

The images or other third party material in this chapter are included in the chapter's Creative Commons licence, unless indicated otherwise in a credit line to the material. If material is not included in the chapter's Creative Commons licence and your intended use is not permitted by statutory regulation or exceeds the permitted use, you will need to obtain permission directly from the copyright holder. 